Citing this article: Rehman, Z., Jaspal, R. \& Fish, J. (in press). Service Provider Perspectives of Minority Stress among Black, Asian and Minority Ethnic Lesbian, Gay and Bisexual People in the UK. Journal of Homosexuality.

\title{
Service Provider Perspectives of Minority Stress among Black, Asian and Minority Ethnic Lesbian, Gay and Bisexual People in the UK
}

\author{
Zaqia Rehman \\ Health and Life Sciences \\ De Montfort University, Leicester, UK \\ Email: zaqia.rehman@dmu.ac.uk \\ Rusi Jaspal \\ Health and Life Sciences \\ De Montfort University, Leicester, UK \\ Email: zaqia.rehman@ dmu.ac.uk \\ Julie Fish, \\ Centre for LGBTQ Research, \\ De Montfort University, \\ Email: $\underline{\text { Jfish@dmu.ac.uk }}$
}

\begin{abstract}
Mental health inequalities among Black, Asian and Minority Ethnic (BAME) people from lesbian, gay and bisexual (LGB) communities persist and remain under-researched. This study is the first in the UK to explore, from the perspective of service providers, minority stress experienced by BAME LGB people. Twenty-three participants were interviewed and data were analysed using qualitative thematic analysis. Minority stress theory was utilised to inform the analysis, yielding the following themes: (1) Stress induced by conflicting sociocultural norms, (2) interpersonal inhibitors of coming out, (3) and problematic coping. BAME LGB individuals are exposed to stressors due to their intersecting sexual, gender, religious, and cultural identities. Major psychological stressors include stigmatised identity, expectations of a heterosexual marriage, and maladaptive coping strategies. This study sheds light on the potential steps that can be taken to ensure effective coping responses among BAME LGB people.
\end{abstract}

Keywords: LGB, ethnicity, mental health, UK, service-provider, minority stress, sociocultural, shame 


\section{Service Provider Perspectives of Minority Stress among Black, Asian and Minority Ethnic Lesbian, Gay and Bisexual People in the UK}

\section{Introduction}

There is now significant evidence that lesbian, gay and bisexual (LGB) people are at a greater risk of poor mental health and attempted suicide in comparison to their heterosexual counterparts (King et al., 2008; McNair, Hegarty, \& Taft, 2012; Meyer, Dietrich, \& Schwartz, 2008; Semlyen, King, Varney, \& Hagger-Johnson, 2016; Silenzio, Pena, Duberstein, Cerel, \& Knox, 2007). LGB people are not a homogenous group, but rather one characterised by social, religious, and socio-economic diversity. The UK is a multicultural society - the Black, Asian and Minority Ethnic (BAME) population has grown from 6.6 million in 2001 to 9.1 million in 2009 (7.9\% - 14.1\%; ONS, 2011). The largest BAME groups consist of individuals of Indian, Pakistani and Black African Caribbean backgrounds. There are approximately 400,000 BAME LGB people in the UK (Stonewall, 2012). While previous research has focused on mental health in LGB communities, relatively little is known about the mental health of LGB people from BAME backgrounds in the UK.

In view of the limited data on BAME communities in health research, this study focuses on the perspectives of service providers working directly with these communities to offer a profile of risk factors in relation to psychological health in this population. This perspective is important because the perceptions held by service providers will in turn shape the nature of their engagement with their clients. The study complements the small body of existing research into social and psychological experiences of BAME LGB people, some of which is discussed below.

The purpose of this paper is two-fold: first, to provide insight to the psychological stressors faced by BAME LGB groups from the perspective of service providers, who themselves were from these communities; and, second, to utilise psychological theory to inform the practice of those working with BAME LGB communities to improve mental health.

\section{Service providers for BAME LGB people}

The service provider role is pivotal and often represents the primary point of contact for a BAME LGB person seeking support. In this study, service providers are viewed as individuals working with a BAME LGB people. One may loosely view the service provider as a primary care space for an BAME LGB individual seeking support. The service provider processes the needs for the BAME LGB individual and signposts them to the correct service (e.g. Social housing). For instance, LGB support services specific for BAME people include sexual health promotion, counselling and social support groups. It is noteworthy that there are no services in the statutory sectors which focus exclusively on the mental health of BAME LGB people in the UK but there are in the voluntary sector from which our participants were recruited. Currently, services for BAME LGB communities are scarce and are often provided by informal non-profit organisations led by volunteers and community members.

Considering the well-documented health inequalities of BAME (Nazroo, 2003; Neeleman, 2001; Marmot, 2010; Department of Health, 2005) and LGB groups (Chakraborty, McManus, Brugha, Bebbington, \& King, 2011; Plöderl et al., 2013), this may 
be problematic. The lack of service provision can exacerbate the risk and severity of mental illness in this at-risk population and demonstrates the need for NHS-led services. Thus, the role of the service provider in ensuring good mental health outcomes is an important one. The service provider, as a first point of contact, possesses the ability to channel clients who are seeking support towards effective coping behaviours which in turn can have long-term health benefits (Jaspal, 2018). The study explores the perspectives of service providers and offers a series of recommendations for enhancing service provision for BAME LGB people.

\section{Minority stress theory}

Minority stress theory (Meyer, 2003) posits that LGB people are susceptible to stress due to their stigmatised minority status in a heteronormative society. According to this theoretical perspective, these stressors can be understood through two distinct categories: Distal stressors are external to the minority individual and include experiences of discrimination, prejudice and stigma.

Proximal stressors are subjective and thus reflect the minority individual's own appraisal of the distal stressors. These include the internalisation of homophobia, expectations of rejection, hypervigilance and concealing one's minority status. The theory considers how distal and proximal stressors interact, as well as ameliorative factors (e.g. social support, coping strategies) that can mediate the relationship between these stressors and the mental health outcomes of LGB communities.

The framework has been useful in explaining the mental health disparities among LGB groups in the UK and studies have validated aspects of the framework. For instance, Timmins, Rimes and Rahman (2017), found prejudice events, expectations of rejection and self-stigma explained distress in transgender individuals in the UK. Likewise, Colledge et al., (2015) utilised Meyer's framework to understand the stress factors related to poorer mental health outcomes for bisexual women compared to lesbian women and found, bisexual women experienced greater stress through internalising stigma of 'double discrimination' related to biphobia and homophobia. In another study, McDermott, Hugh's and Rawlings (2018) found discrimination, victimisation and stigma related to LGB identity as important predictors of suicidality in LGBT youth. Moreover, when applied to qualitative reaserch, recent empirical work shows Meyer's (2003) explanatory model offers greater insight on the role of minority stress among LGB people (Fish \& Williamson, 2016). However, a notable gap in the literature on Minority Stress theory is that we could not locate research on the mental health of BAME LGB communities in the UK.

\section{The Mental Health of BAME LGB people in the UK}

There are no published studies in the UK that solely address the prevalence of mental illness, such as suicidal ideation, distress, self-harm, anxiety and stress, in the BAME LGB population. Published research into the health and wellbeing of BAME LGB individuals can be divided into two broad categories. Some research has been conducted in HIV and sexual health among BAME gay, bisexual and other men who have sex with men (Dougan, Patel, Tosswill, \& Sinka, 2005; Fish, Papaloukas, Jaspal, \& Williamson, 2016; Hickson et al., 2004; McKeown et al., 2012; Soni, Bond, Fox, Grieve, \& Sethi, 2008). There have been several studies of identity processes and the 'coming out' experiences of BAME LGB people, which - with the exception of a few studies (Siraj, 2011; 2018a; 2018b, Yip, 2004a; 2004b) - has 
greater emphasis on South Asian gay and bisexual men (Bhugra, 1997; Jaspal, 2012, 2014, Jaspal \& Cinnirella, 2010, 2014; Jaspal \& Siraj, 2011).

Moreover, with the exception of Siraj (2011), even within the small extant literature, lesbian and bisexual women from BAME communities are under-represented in the UK. Nair (2006) argues that BAME LGB individuals face multiple levels of discrimination which can adversely affect their mental health and subjective well-being, and grouped the vulnerabilities into the following two categories: External variables (homophobia, lack of support, lack of services, racism, and poor visibility). Internal variables (low self-esteem, coming out, identity, isolation, internal homophobia, and racism).

From a minority stress perspective, Nair (2006) demonstrates the overlapping vulnerabilities of external and internal variables including homophobia, racism, coming out and lack of support which may cause unique stress for BAME LGB people. However, there is no empirical data to ascertain the prevalence of poor mental health in the UK population. BAME LGB people may not identify with the western concepts of 'lesbian' 'gay' and 'bisexual' (Fish, 2008) which in turn may explain their poor participation rates in surveys (Kim \& Fredriksen-Goldsen, 2013) that attempt to address mental health (King et al., 2008; Semlyen et al., 2016).

The psychological stressors associated with being of sexual and ethnic minority backgrounds may increase the risk of poor mental health. BAME LGB people experience internalised homophobia (Barnes \& Meyer, 2012), heterosexism (Sung, Szymanski, \& Henrichs-Beck, 2015) hypervigilance (Jaspal et al., 2017) and a lack of social support (Jaspal, 2014) and engage in maladaptive behaviours (Ayala et al., 2012). Yet, the question of whether the effects of multiple stigmatised identities are additive or synergistic (Cochran, 2001) has not yet been addressed in the UK context.

\section{Multiple marginalisation and mental health}

In the US, there has been increased focus on multiple marginalised identities and the implications for minority stress. In their study, Meyer, Dietrich and Schwartz (2008) explored the prevalence of mental disorders among Black and Latino versus White LGB people and found Black and Latino LGB individuals have lower prevalence of mental disorders but elevated rates of suicidality compared to their white counterparts. An important finding of the study was that the age of suicide attempt in minority groups was before 20, suggesting difficulties in coping with early adversity (Meyer et al., 2008). Researchers predict that suicide risk among Black and Latino LGB people is more strongly related to major stressful events associated with coming out, such as assault, abuse and homelessness, than to depression and other mental disorders (Haas et al., 2011). However, these US-based data cannot easily be generalised to the UK context, as there are differences in ethnicity, education, social economic status and epidemiology.

In contrast, a UK study of mental health, sexual orientation and gender identity revealed that BAME LGB respondents were less likely than white LGB respondents to have considered suicide (King et al., 2003). Crucially, a binary definition of sexuality was used in the analysis and the study was unable to assess the impact of 'double discrimination' owing to the limited BAME LGB sample (Warner et al., 2004). Although the UK-based study does not explore the impact of dual minority status, several other studies from the US support the observation that those who identify as both sexual and ethnic minorities are at heightened risk of suicide (Meyer et al., 2008; Mustanski, Garofalo, \& Emerson, 2010). 
However, it is important to recognise the potential differences between BAME groups of LGB people in their social and psychological experiences, risk factors and behaviours (Keogh et al., 2004). While Minority Stress Theory suggests that multiply marginalised groups are at higher risks of poor psychological health because of the cumulative effects of racism and homophobia, studies of resilience suggest that the intersections of race and sexuality may serve as a protective factor to stress (Bostwick et al., 2014)

The studies reviewed provide insight into a significant, though largely underinvestigated, population and into the complexities of marginalised identities and psychological health. Building on this emerging evidence of poor mental health in BAME LGB people, the current study employs a qualitative approach to explore the contexts in which stress may develop and affect the mental health of BAME LGB people.

\section{Method}

\section{Participants}

Twenty-three service providers working with BAME LGB groups were interviewed for this study. There were 12 males and 11 females. Eleven self-identified as British/ Asian Indian, 6 as British/ Asian Pakistani, 3 as White, 2 as dual ethnicity, and 1 as Black African Caribbean. Recruitment was purposive through online sources. The participants represented various formal and informal organisations located across the UK and occupied both remunerated and voluntary positions. This sample included community support workers, LGBT BAME researchers, counsellors, psychotherapists, service managers, sexual health workers, outreach workers and general support workers.

A purposive sampling strategy was used to recruit a diverse range of service providers working with BAME LGB communities to offer multi-faceted insight into BAME LGB mental health (Palinkas et al., 2015). The first author developed substantial networks during the year preceding data collection, established two social media groups, and undertook volunteer work among BAME LGB communities. As the first author had begun to establish herself in the field, potential participants were recruited relatively quickly. Participants were included if they held, or had previously held, a substantive role working with BAME LGB individuals.

\section{Procedure and data collection}

Interviews were guided by a semi-structured interview schedule which included 13 open-ended questions. The interview schedule comprised key domains relating to service providers' perceptions of, and experiences of, working with LGB BME clients, focusing on characteristics of the BAME LGB community, common stressful experiences, mental health and wellbeing, perceived differences from the general LGB community, coming out experiences, support networks and access to services. One-to-one interviews were conducted at a location convenient for the participant. The interviews lasted between 50-120 minutes and were digitally recorded and transcribed verbatim. 


\section{Analytical procedure}

The data were analysed using qualitative thematic analysis, which has been described as 'a method for identifying, analysing and reporting patterns (themes) within data' (Braun \& Clarke, 2006, p. 78). The approach was considered useful in conjunction with Minority Stress Theory, as it can enable the analyst to identify and describe the proximal and distal stressors experienced by clients, focusing on the ways in which they experience social psychological constructs, such as sexuality, ethnicity and stigma. In this study, thematic analysis was used to identify themes in the data that shed light on how particular interpersonal and intergroup experiences might represent a psychological stressor, thereby potentially challenging mental health among clients. Specific interview extracts, which were considered vivid, compelling and representative of the themes, were selected for presentation in the final research report.

\section{Results and Discussion}

In this section, the following themes are discussed: (1) stress induced by conflicting sociocultural norms, (2) interpersonal inhibitors of coming out, (3) and problematic coping, which reflect this cohort of service providers' perceptions concerning the mental health of BAME LGB people in the UK.

\section{Stress induced by conflicting sociocultural norms}

This theme focuses on the proximal stressors that arise from the identity conflicts associated with being BAME LGB, from the perspective of service providers. These stressors can be attributed to the presence of norms that essentially stigmatise homosexuality and tenets of ethnic and religious culture that guide perceptions. These include compulsory heterosexuality, ethno-religious stressors and family expectations.

\section{The impact of 'compulsory heterosexuality'}

Rich (1980) coined the term 'compulsory heterosexuality' which we adapt here to highlight normative assumptions of opposite sex relationships and traditional marriage or normative gender expectations. For example, participants described the expectations of a heterosexual marriage as potentially compromising self-esteem among BAME LGB people:

"For example, if some woman is attracted to women only and her family are saying she will get married to a man and that's the only way, that's the only path in life to go with, that can have a big impact on her self-confidence and self-esteem." (Tasin, male, social support work)

In this extract, the familial setting is the primary site of heterosexual socialisation and marriage is expected of BAME LGB people as a cultural norm from a young age. Within South Asian communities, young people are often reminded of their religious and cultural obligation to get married (Jaspal, 2014). The violation of the cultural norms can result in negative interpersonal relationships (Jaspal and Siraj 2011) and in the LGB person being viewed as 'abnormal' or even sinful (Herek, 2004). Thus, cultural norms can form an additional layer of minority stress (Dispenza, Brown, \& Chastain, 2016) including the minority status of being both gay and from an ethnic minority group (Szymanski \& Kashubeck-West, 2008). 
A US study on Asian American sexual minorities revealed that heterosexism in ethnic communities was a predictor of psychological distress and that it was especially distressing when heterosexism was received from significant others in one's ethnic community (Szymanski \& Sung, 2010). Indeed, Tasin's account describes how the pressures of a heterosexual marriage can lead to a sense of conflict and thus challenge psychological wellbeing among those who identify as LGB. These accounts illustrate the proximal stressors experienced by BAME LGB people in their own communities:

"To generalise, most families say that marriage is the right way and that it should be between a man and a woman." (Arshad, male, support worker)

"If you feel like you're not part of this norm - this heteronormative norm - maybe you feel feminine or masculine or you have desires for something that is not talked about, even sex is generally not discussed in these communities." (Harjit, male, board member)

Harjit's account reflects a form of heterosexism, namely the silencing of sexualityrelated matters due to conservative cultural norms found in some BAME communities (Gilligan and Akhtar 2006). Arshad discusses heterosexism in relation to marriage and widespread cultural perceptions of a 'right' form of marriage (e.g. between men and women), which in turn constructs same-sex relationships as wrong.

Psychological research has shown that some BAME LGB people experience conflicts in relation to their sexuality and ethnicity (Jaspal, 2014). Sexual minorities are "likely to be subject to such conflicts because the dominant culture, social structures, and norms do not typically reflect those of the minority group" (Meyer, 2003, p. 675). Balsam et al. (2011) explored experiences of heterosexism and racism among BAME LGB people and found that heterosexism within BAME communities had a greater negative impact on mental health than racism. BAME LGB people in the UK continue to contend with social stigma and negative stereotyping on the basis of both sexuality and ethnicity (Siraj, 2009), despite advances in challenging homophobia and in promoting ethnic equality in Britain.

\section{Ethno-religious stressors and family expectations}

This sub-theme aims to contextualise the ways in which family, upbringing and perceived cultural and religious values interact and potentially generate psychological stress. These stressors are driven by the cultural representations of sexuality and shape individuals' views regarding their own sexual identity. The limited and stigmatising terminology and cultural misperceptions can in turn induce homophobic attitudes:

"If your parents are from a culture where homophobia is like accepted and its part of - like my dad is from Jamaica and - the dominant dialogue around LGBT people in Jamaica is very homophobic." (Lauren, female, social support work)

"Even though our religions are saying one thing - within the Hindu and Sikh communities it says one thing - and then people are using the religion to say actually gay people are disgusting, they are vile, they are the lowest of the low, they are paedophiles and so forth." (Vijay, male, sexual health support services)

The service providers discuss the manifold forms of prejudice observable in BAME communities. Lauren regards pejorative attitudes surrounding homosexuality as a culturally embedded element carried over from her father's native country. Vijay believes that 
homophobia is contingent on culture and that religious scripture is deliberately deployed as a means of substantiating homophobic norms. In previous research, gay Pakistani men described the homophobic religious representations in the Qu'ran as misunderstandings arising from human interpretation (Jaspal and Cinnirella, 2010).

BAME LGB people are increasingly aware of the negative stereotypes surrounding homosexuality within their community and, in some cases, apply these stereotypes to themselves (Ryan \& Futterman, 1998). Given the hegemony and pervasiveness of such stereotypes, individuals may have little choice but to accept and internalise them (Jaspal \& Coyle 2009). Minority Stress Theory refers to this as internalised homophobia (Meyer, 2003), that is, "the gay person's direction of negative social attitudes toward the self, leading to a devaluation of the self and resultant internal conflicts and poor self-regard" (Meyer \& Dean, 1998, p. 161). The service providers generally empathised with their clients, sometimes due to their own experiences of heterosexism. For instance, several service providers recognised how religious belief systems might contribute to negative self-regard among their clients:

'I used to feel very uncomfortable going to the Sikh temple. I used to feel I was wrong and what I was feeling and how I was behaving was not in line with the religion.' (Harjit, male, board member)

“...the majority of Pakistani people are Muslim and their faith, the family or themselves are not able to resolve their sexual orientation with their religion - their faith." (Clare, female, social support work)

The data above illustrate the processes of the proximal and distal stressors that lead to poor mental health in BAME LGB people. Harjit describes his own experiences of internalised homophobia and incorporates the negative societal views of homosexuality into his self-concept, which in turn exacerbates the intrapsychic conflict between his same-sex desire and the perceived need to be heterosexual (Hatzenbuehler, 2009; Herek, 2004).

In a meta-analysis (Newcomb \& Mustanski, 2010), internalised homophobia was associated with symptoms of depression and anxiety. Internalised homophobia is a core concept of Minority Stress Theory and considered to be an antecedent to additional negative health outcomes, such as sexual risk behaviour and substance use (Williamson, 2010). Difficulties experienced in constructing and reconciling sexual and ethno-religious identities can result in a lack of psychological coherence (Jaspal and Cinnirella 2010). In this study, several participants employed the term 'religious guilt' to describe their experience of navigating competing sociocultural norms:

"I met somebody and yes, as Katy Perry sings, 'I kissed a boy and I liked it' [sic]. But I liked it - but I carried a lot of religious guilt with me." (Arshad, male, social support worker)

"Whereas for like Hindu, Sikhs and Buddhist we don't have any text or anything that we play or can play. It's just more of - it's not a sin thing in our culture and in our culture its seen as a man should be with a women even though historically that may not have been the case with certain groups. So I think that adding religion aspect can put a twist on it." (Harjit, male, board member)

Arshad applies his own experience to illustrate the internal tension. While Harjit's excerpt alludes to the non-affirming religious text to explain where the tension may arise for some BAME LGB individuals. Guilt has been associated with psychopathologies (TilghmanOsborne et al., 2010), while irreconcilable religious and sexual identities may contribute to 
internalised homophobia (Ream and Savin-Willams 2005). In a study exploring religious affiliation and internalised homophobia (Barnes and Meyer 2012), high levels of internalised homophobia were found in Latinos who were exposed to non-LGBT affirmative religious settings. There is also some evidence that family and religious values are important drivers of sexuality-related guilt.

Gravel et al., (2011) investigated ethnic differences in sexuality-related guilt and found that Anglo-Canadians reported higher levels of sexual guilt than French Canadians; lower sexual permissiveness and higher religious values were stronger in Anglo-Canadians than French Canadians and acted as mediators of sexuality-related guilt. While their findings are based on young heterosexual students, they are in parallel to findings regarding nonheterosexual religious groups. In the UK context, it has been observed that British Indian LGB people generally experience difficulties in reconciling their sexuality and ethnicity, while British Pakistani LGB people experience challenges in reconciling their sexuality, ethnicity and religion (Jaspal, 2012). These complex experiences at the intersection of religion, culture and family may discourage the BAME LGB person from disclosing their sexual identity to significant others and, thus, from seeking social support.

\section{Interpersonal inhibitors of coming out}

Given the stigma experienced by LGB people, service providers noted resistance in disclosing their sexual identities and identified the following barriers: expectations of rejection, sexuality-related stigma and the risk of discrediting family honour.

\section{Stressors of stigma and expectations of sexual identity rejection}

Stigma is defined as a social devaluation of a person or group on the basis of a particular attribute (Goffman, 1963). Minority Stress Theory refers to expectations of rejection as an internal stressor - the LGB individual comes to anticipate negative regard from members of the dominant culture (Meyer, 2003). Data illustrated the social stigma attached to LGB identity and clients' expectations of rejection from significant others. Participants recounted occurrences of clients feeling apprehensive about disclosing sexual identity to the family due to their anticipation of negative outcomes, including losing family and financial support, disownment, loneliness and, in some cases, violence, and homelessness, coercion into marriage, or being sent to their parents' country of origin. The data highlight anticipated stigma in the event of coming out:

"The main reasons why people feel that they are unable to initiate those conversations of coming out with families is fear of rejection, fear of dishonouring family, fear of bringing shame, fear of causing ill health and pain, a fear of being isolated and the fear of being ostracised." (Praneeta, female, LGBT Service manager)

Praneeta provides a succinct summary of the negative outcomes her clients envisaged in relation to sexual identity disclosure to the family. Within BAME communities, which tend to have a collectivist cultural orientation, the family is integral to identity (Fouad et al., 2008; Oyserman, Coon, \& Kemmelmeier, 2002). Thus, fear of losing one's family can preclude coming out (Jaspal, 2018). This study revealed a distinction between anticipating rejection of the sexual identity and rejection of the LGB person: 
"One of the last calls I got was from this girl from a Somalian community and she had grown up in England. She was born here, and she was telling me how somebody else in the community had come out as being a lesbian and she got sent back to Somalia. Nobody has seen her since and she was really worried that this is going to happen to her." (Sneha, female, BAME, Lesbian and Bisexual women's support officer)

As is the case for Sneha's caller, the disclosure experience is complex and is shaped not only by her current social context but also by her past experiences of discrimination (Ragins, Singh, \& Cornwell, 2007). In comparison to the general LGB population, BAME LGB individuals are at increased risk of being coerced into a heterosexual marriage if they disclose their sexual identity to their parents. Moreover, Minority Stress Theory suggests past experiences of discrimination heighten hyper-vigilance and expectations of rejection (Meyer, 2003). In a study examining stigmatised concealed identities (Quinn \& Chaudoir, 2009), anticipated stigma was a strong predictor of increased depression and anxiety. Research examining stigma-related stress among LGB groups has consistently revealed negative mental health consequences (Frost, 2011). An aspect of the stigma-related stress is the fear of damaging family honour.

\section{Stress of discrediting one's family: shame and honour}

Shame is a self-conscious emotion involving a negative self-evaluation following violation of the social group norms (Dolezal \& Lyons, 2017). In LGB South Asian communities, concepts of 'honour' and 'shame' were consistently cited as impeding coming out:

"Even in 2016, it [honour] is such a big issue which I personally find so hard to believe but it is still a massive issue. I think even British Asians have it in them as well. This idea of 'bezati' and this idea of 'besharmi' and stuff it means more to people than the love of their own children or their brothers and sisters." (Asim, male, health promotion and outreach work).

"Sometimes it's not the family's opinions and I think culturally somebody may go 'I'm okay with this' but the bigger picture is what the community will say. Families are very much forced about values about what the community is going to say." (Amir, male, health promotion and outreach work)

In many South Asian communities, izzat (honour/respect), haya (modesty) and sharam (shame/embarrassment) are crucial determinants of sexual identity construction and disclosure (Gilligan and Akhtar, 2006; Jaspal, 2020). The term 'bezati' refers to disrespect in the community - often as a result of a family member's activities. Asim accentuates the gravity of 'bezati' which takes precedence over the desires of loved ones including, siblings and children. LGB individuals often feel the burden of 'izzat' because they may believe that their actions could undermine it. While Asim considers the honour-based codes as outdated principles, three participants employed the term 'indoctrination' to illustrate the internalisation of these cultural values among younger BAME LGB people:

"Again, this is indoctrination isn't it; it's about people saving face, saving honour, and all that kind of malarkey." (Arshad, male, social support work)

This study deems izzat as a pervasive, internalised and reinforced value (ChewGraham, et al., 2002) which induces the need to conceal the stigmatised sexual identity 
(Chekola \& McHugh, 2012). Damaging the family's izzat leads to shame within the community and increases the risk of becoming the target of community gossip, 'fingerpointing' and ridicule (Toor, 2009). LGB individuals feel obligated to uphold traditional expectations and preserve family honour. Contravention of izzat can lead to marginalisation and disownment (Gilbert et al., 2004). David described the significance of these constructs in people's lives:

"The reason for that [non-disclosure] would be because of the rejection, because of the stigma, because of the shame they feel they would bring on their family; their family would project on to them and there were just too many things that would unravel in their lives if they came out as gay." (David, male, counselling services)

David indicated that some BAME LGB people might prefer simply not to disclose their sexual identity to others in order to avoid difficulties in their lives. For instance, disclosure may be overridden by the desire to 'protect' loved ones from community shame. Demonstrating the importance of honour, Gilbert et al. (2004) collected data from South Asian women to explore the use of mental health services and processes of shame/ and izzat emphasising that suicide was a preferable alternative to disclosing the status of one's mental illness. In this study, shame and honour exacerbate stigma-related stress and impose a cognitive burden on the BAME LGB person.

Shame is related to high levels of concealment (Quinn \& Chaudoir, 2009) and to poor mental health in sexual minorities (Kim, Thibodeau, \& Jorgensen, 2011). While much LGBT research focuses on the benefits of coming out for psychological wellbeing (Morris, Waldo, \& Rothblum, 2001), these benefits can only be realised if one receives a positive response to one's coming out (Quinn \& Chaudoir, 2009). In response to psychological stress, individuals attempt to cope. Some of these strategies may be maladaptive and problematic.

\section{Problematic coping}

Minority Stress Theory suggests that the interaction of internal and external stressors, in the absence of perceived support, will culminate in a poor coping response, increasing the risk of mental illness (Meyer 2003). Coping with stress generally takes two forms; emotionfocussed coping which regulates the emotional response to the problem, and problemfocussed coping which actively manages the causal factor in the stress (Lazarus and Folkman 1984). Service providers described both of the coping methods that BAME LGB people adopt in order to cope with stress. The study shows compartmentalising identities was used as a problem-focussed coping strategy and emotion focused coping methods included selfdestructive behaviours.

\section{Compartmentalising LGB identities}

This sub-theme provides insight into the lived experience of leading a 'double life' and the difficulties experienced by BAME LGB people in establishing a balance between their social and individual identities. Amir recalls how a South Asian gay man compartmentalised his private gay identity to protect his hetero-social identity and vacillated between the two in order to maintain a covert intimate relationship with another man:

"In order to spend time with his boyfriend, he told his family he works in London. What he does is, he manages not being seen in any city by mirroring the diary [of what] his family are doing: school runs, evenings, weddings, and he does that on a weekly basis. That's the extreme and that's how he doesn't come face-to-face and he 
has done that for eight months. Now, him coming to that - when we talk about mental health - he came in to talk about 'it's really eating me up" (Amir, male, health promotion and outreach work).

Compartmentalisation has been referred to as the psychological practice of attenuating one identity in favour of another, particularly in social contexts (Breakwell 1986). The interviews highlight a fear of involuntary disclosure of sexual identity and individuals deploy a problemfocussed coping strategy (Lazarus and Folkman, 1984). This sometimes involves falsifying information to conceal the truth which can descend into a 'tangled web-phenomenon', whereby telling one lie leads to more lies (Chekola \& McHugh, 2012).

Amir describes the stressful implications for mental health. For example, the metaphor 'it's really eating me up' expresses the pressures of maintaining a false identity and the chronic threat of being exposed. Pachankis' (2007) model describes four specific components of concealing a stigmatised identity: cognitive (e.g. preoccupation, vigilance and suspiciousness), affective (e.g. anxiety, depression, hostility, guilt and shame) behavioural (e.g. impression management, social avoidance) and self-evaluation (e.g. negative view of self, identity ambivalence diminished self-efficacy). In Amir's extract, the service user's double life commands the cognitive preoccupation of vigilance to avoid an involuntary social encounter with family members. In addition to social avoidance and impression management, the study also revealed cognitive dissonance in the self-concept (Pachankis 2007):

"Living a double life is so hard because you are constantly - this is from [personal] experience as well, it's draining on the person. You are never true to yourself as a person and you kind of lose yourself. I guess one would lose themselves in that situation." (Farhana, female, lesbian bisexual Muslim women's officer)

Farhana draws upon her own experiences of struggling with the intrapsychic conflict between her hetero-social and lesbian identities. Farhana's sense of authenticity is compromised in the effort to uphold the two identities (Jaspal 2012). Participants reported that there was a tendency among BAME LGB people to disclose and display their true sexual identity to some people while maintaining a public hetero-social identity within their ethno-religious communities. In some cases, this involved feigning a heterosexual life and even embarking on a (heterosexual) marriage of convenience - by marrying a gay/ lesbian cisgender individual seeking a heterosexual marriage. A marriage of convenience created additional complications, in what Goffman (1963) refers to as 'in-deeper-ism' (creating more and more lies to avoid disclosure).

For some individuals, concealing a stigmatised identity may be functional (i.e., situationally protective) even though the consequences of doing so are maladaptive (i.e., increased symptomatology, limited support) (Quinn et al., 2014). The data in this study indicate the notion of 'in-deeeper-ism' and the constant attention required to conceal sexual identity creates a stressor in the lives of non-disclosing individuals (Schrimshaw, Siegel, Downing \& Parsons, 2013).

\section{Emotion focussed coping}

Participants also described the emotion-focused forms of coping designed to reduce the negative emotional distress of the perceived threat (e.g. unintended disclosure) (Lazarus 1999; Lazarus \& Folkman 1984). In this study, alcohol and substance use featured strongly as coping mechanisms (Cooper, Cooper, Russell, \& George, 1988): 
"But I know quite a few of them (BAME gay and bisexual men) are talking about using alcohol as a way to almost keep mind and body together and to stop their-they were talking about their heads and minds just wanted to explode from the pressure they were under." (David, male, counselling services)

"I have seen people from the community outside of this service, coping in very different ways. For example, going back to the drug thing, a lot of people do turn to drugs unfortunately and its become more and more of an issue at the moment because it's so accessible." (Farhana, female, lesbian bisexual Muslim women's officer)

David defines alcohol as a form of cognitive avoidance that provides temporary respite from perceived stress (Jaspal 2018). Consistent with previous research, substance use and problematic drinking were found to be higher amongst those expecting to regulate negative emotions about a stressful situation (Wagner, Myers, \& McIninch, 1999). Furthermore, research from the US reveals that sexual minority women of racially diverse backgrounds reported higher rates of substance use than both heterosexual and White sexual minority women (Mereish \& Bradford, 2014).

In some situations, participants highlighted self-harm as a form of coping, that is, to alleviate the negative affect (see Klonsky, 2007):

"Each individual might be different, but my own thoughts are that perhaps they [LGB $B A M E]$ don't like themselves very much. So there is a lack of self-acceptance and that might lead on to other feelings of perhaps suicidal thoughts or self-harm." (Saif, male, LGB Muslim support work)

"They talked about it how; they weren't going to be accepted by their families and if she went back home, how is she going to get back out again. So, one way of kind of coming to terms with it, was through self-harming really." (Suki, female, LB support worker)

Saif and Suki construct self-harm as a response to internalised homophobia and self-loathing which arise in some BAME LGB people. Research suggests that social support networks may mediate the risk of psychological distress and maladaptive coping (Jaspal 2018). Through their daily interactions with BAME LGB people, service providers are potentially influential in driving better mental health outcomes by acting as role models and sharing positive coping strategies. They can facilitate social spaces for BAME LGB people and offer opportunities for informal social support.

\section{Conclusions}

This is the first study of mental health in BAME LGB people in the UK from the perspectives of service providers. Using Minority Stress Theory, the findings suggest that the intersections of sexual orientation, gender, and religion can increase the risk of psychological stress for BAME LGB people. The service provider's perspective is important because the service provider has the potential to promote effective coping strategies among their BAME LGB clients.

Previous research people highlights the challenges associated with multiple, intersecting identities in BAME LGB people (e.g. Jaspal, 2018). The present study builds on this existing research by elucidating the unique pathways to major stigma-related stress, which extend beyond the constructs of distal and proximal stressors. Crucially, it was found 
that notions of honour and shame are central to identity functioning and cultural consciousness in some BAME communities (Jaspal, 2020). These important identity elements form guiding principles but may also be invoked to rationalise, and thus perpetuate, LGB prejudice within BAME communities. This is a significant departure from Minority Stress Theory, because honour and shame perform some important functions for identity, such as the provision of a sense of cultural and familial continuity, but they are also psychological 'barriers' to assimilating and accommodating an LGB identity. In particular, sexual identity stigma, family honour and the perceived community stigma impose a psychological burden to conceal LGB identity. This demonstrates the need to revisit and refine elements of Minority Stress Theory when applied to under-explored ethnic and cultural communities. In parallel with previous research, anticipated stigma of a socially devalued identity is associated with higher levels of distress (Quinn et al., 2014) and poor psychological health in LGB populations (King et al., 2008).

Awareness of potential risks associated with identity concealment (e.g. maladaptive coping, internalised homophobia, hyper vigilance, expectations of rejection, remunerating) must be raised within professional practitioners and in BAME LGB services. Some of these strategies may be effective in the short term given that they enable the individual to deflect the stressors that ordinarily challenge their psychological wellbeing but they are unlikely to be sustainable over time and may come to pose separate threats to wellbeing in the long term. For instance, by concealing one's sexual identity from other people, one is less likely to be exposed to social stigma but one's access to social support is vastly reduced (Breakwell, 1986).

In addition, the current study highlights the need for further research into the distinctive role of internalised stigma (applying the negative stereotypes of the stigmatised identity to oneself), anticipated stigma (negative treatment one expects in the event of disclosing the stigmatised identity) and cultural stigma (devaluation of the stigmatised identity by community, which is a process external to the stigmatised individual) (Quinn \& Chaudoir, 2009) on the mental health of LGB people.

There is a significant need to invest in resources to facilitate social and support spaces for the non-heterosexual BAME community. For example, BAME LGB people socialised in a non-LGB affirmative environment may come to internalise homophobic stigma which can in turn lead to guilt and poor mental health outcomes. However, the key to successful coping is to encourage linkage to positive support networks (e.g. LGB friendship groups) to buffer the negative effects of engaging with non-affirmative environments (Kocet, 2014). Service providers may be able to facilitate and encourage positive coping strategies of this kind among their clients. There is a need for service provider integration and collaborative work with existing mental health services which could help bridge the gap between knowledge and service provision.

A key finding from this study is that a culturally competent service is likely to be most effective in identifying mental health risk factors and maladaptive coping patterns in BAME LGB (Fish et al., 2016). The service providers who participated in this study were from BAME communities and, thus, possessed an element of lived experience in relation to the issues they identified in their clients. It is important that service providers, regardless of their own ethnic and cultural background, be empowered to work effectively with BAME clients. More specifically, health service providers must understand the social, cultural and religious contexts in which their clients are embedded, as the norms, values and representations associated with these contexts will shape both their experiences and the coping strategies they utilise. Service providers can offer emotional and informational 
support and encourage BAME LGB individuals to use ameliorative coping techniques (Jaspal 2018). They can facilitate access to social support, explore the feasibility of sexual identity disclosure, and facilitate effective ways of resolving the intrapsychic conflicts that cause stress and undermine wellbeing in BAME LGB people.

\section{Limitations}

A limitation of this study included the use of a purposive sample of BAME LGB professionals which was not necessarily representative of the BAME LGB community. It would be advantageous to replicate this study in other BAME communities that are not currently represented in the present study. However, the exploratory nature of the study sought to identify the mental health challenges and using a diverse service provider perspective was effective in identifying the key factors in psychological health. Given the diverse sample, we were unable to examine systematic differences between particular BAME subgroups. Further research is needed across the BAME communities to address the heterogeneity and within-group differences. The focus of this study was on the psychological challenges faced by individuals and future research ought to focus on resilience and successful integration of a BAME and LGB identity.

\section{Summary}

This study responds to the gap in knowledge on the mental health of BAME LGB people in the UK. Mental health service providers indicate that their BAME LGB clients contend with perceived conflict between their sexuality, religion, honour and stigma. In the absence of effective social support, many deploy maladaptive strategies for coping with the resulting psychological stress. Both the stress itself and the coping strategies used can undermine mental health outcomes in this population. Many problems identified in the paper are long-standing and BAME LGB people should be encouraged and empowered to seek support. This study generates insights for policy makers, LGBT services and mental health practitioners to incorporate cultural competence into mental health service provision for BAME LGB people. 


\section{References}

Ayala, G., Bingham, T., Kim, J., Wheeler, D. P., \& Millett, G. A. (2012). Modeling the impact of social discrimination and financial hardship on the sexual risk of HIV among Latino and Black men who have sex with men. American Journal of Public Health, 102(SUPPL. 2), 242-249. https://doi.org/10.2105/AJPH.2011.300641

Barnes, D. M., \& Meyer, I. H. (2012). Religious Affiliation, Internalized Homophobia, and Mental Health in Lesbians, Gay Men, and Bisexuals. American Journal of Orthopsychiatry, 82(4), 505-515. https://doi.org/10.1111/j.1939-0025.2012.01185.x

Bhugra, D. (1997). Coming Out by South Asian Gay Men in the United Kingdom. Archives of Sexual Behavior, 26(5), 547-557. https://doi.org/10.1023/A:1024512023379

Bostwick, W. B., Meyer, I., Aranda, F., Russell, S., Hughes, T., Birkett, M., \& Mustanski, B. (2014). Mental health and suicidality among racially/ethnically diverse sexual minority youths. American Journal of Public Health, 104(6) 1129-1136. https://doi.org/10.2105/AJPH.2013.301749

Braun, V., \& Clarke, V. (2006). Using thematic analysis in psychology. Qualitative Research in Psychology, 3(2), 77-101. https://doi.org/10.1191/1478088706qp063oa

Breakwell, G. M. (1986). Coping with threatened identities. London, England: Methuen.

Chakraborty, A., McManus, S., Brugha, T. S., Bebbington, P., \& King, M. (2011). Mental health of the non-heterosexual population of england. British Journal of Psychiatry, 198(2), 143-148. doi:10.1192/bjp.bp.110.082271

Chekola, M., \& Arden McHugh, N. (2012). The ontological foundations of passing. In D. Cooley, \& K. Harrison (Eds.), Passing/out: Sexual identity veiled and revealed (pp. 1342). London: Routledge.

Chew-Graham, C., Bashir, C., Chantler, K., Burman, E., \& Batsleer, J. (2002). South Asian women, psychological distress and self-harm: lessons for primary care trusts. Health \& Social Care in the Community, 10(5), 339-347. https://doi.org/10.1046/j.13652524.2002.00382.x

Cochran, S. D. (2001). Emerging issues in research on lesbians' and gay men's mental health: Does sexual orientation really matter? American Psychologist, 56(11), 931-947. https://doi-org.proxy.library.dmu.ac.uk/10.1037/0003-066X.56.11.931

Colledge, L., Hickson, F., Reid, D., \& Weatherburn, P. (2015). Poorer mental health in UK bisexual women than lesbians: evidence from the UK 2007 Stonewall Women's Health Survey. Journal of Public Health, 37(3), 427-437.

Cooper, M. L., Russell, M., \& George, W. H. (1988). Coping, expectancies, and alcohol abuse: A test of social learning formulations. Journal of Abnormal Psychology, 97(2), 218-230. doi:10.1037/0021-843X.97.2.218

das Nair, R. (2006). "Metaminorities and Mental Health: Pathways of vulnerability for Black and Minority Ethnic Queer Folk”, Inter-disciplinary Net: Oxford.

Department of Health (2005). Delivering race equality in mental health care: An action plan for reform inside and outside services and the Government's response to the independent inquiry into the death of David Bennett. Retrieved from: http://www.doh.gov.uk/publicationsandstatistics/publications/publication 
spolicyandguidance

Dispenza, F., Brown, C., \& Chastain, T. E. (2016). Minority Stress Across the CareerLifespan Trajectory. Journal of Career Development, 43(2), 103-115. https://doi.org/10.1177/0894845315580643

Dolezal, L., \& Lyons, B. (2017). Health-related shame: An affective determinant of health? Medical Humanities, 43(4), 257-263. https://doi.org/10.1136/medhum-2017-011186

Dougan, S., Patel, B., Tosswill, J. H., \& Sinka, K. (2005). Diagnoses of HIV-1 and HIV-2 in England, Wales, and Northern Ireland associated with west Africa. Sexually Transmitted Infections, 81(4), 338-341. https://doi.org/10.1136/sti.2004.013011

Fish, J. (2008). Navigating queer street: Researching the intersections of lesbian, gay, bisexual and trans (LGBT) identities in health research. Sociological Research Online, 13(1-2) doi:10.5153/sro.1652

Fish, J., \& Williamson, I. (2016). Exploring lesbian, gay and bisexual patients' accounts of their experiences of cancer care in the UK. European Journal of Cancer Care, 27(1), e12501. doi:10.1111/ecc.12501

Fish, J., Papaloukas, P., Jaspal, R., \& Williamson, I. (2016). Equality in sexual health promotion: A systematic review of effective interventions for black and minority ethnic men who have sex with men. BMC Public Health, 16(1), 1-18. doi:10.1186/s12889-0163418-x

Fouad, N.A., Kantamneni, N., Smothers, M.K., Chen, K.-L., Fitzpatrick, M., \& Terry, S. (2008). Asian American career development: A qualitative analysis. Journal of Vocational Behavior, 72, 43-59

Frost, D. M. (2011). Social Stigma and its Consequences for the Socially Stigmatized. Social and Personality Psychology Compass, 5(11), 824-839. https://doi.org/10.1111/j.17519004.2011.00394.x

Gilbert, P., Gilbert, J., \& Sanghera, J. (2004). A focus group exploration of the impact of izzat, shame, subordination and entrapment on mental health and service use in South Asian women living in Derby. Mental Health, Religion and Culture, 7(2), 109-130. https://doi.org/10.1080/13674670310001602418

Gilligan, P., \& Akhtar, S. (2006). Cultural barriers to the disclosure of child sexual abuse in asian communities: Listening to what women say. The British Journal of Social Work, 36(8), 1361-1377. doi:10.1093/bjsw/bch309

Goffman, R (1963) Stigma: Notes on the Management of Spoiled Identity Englewood Cliffs NJ Prentice-Hall

Gravel, E. E., Young, M., Olavarria-Turner, M., \& Lee, A. M. S. (2011). Ethnic differences in sexual guilt between anglo-canadians and franco-québécois emerging adults: The mediating roles of family and religion. Canadian Journal of Human Sexuality, 20(4), 129-142.

Hatzenbuehler, M. L. (2009). How does sexual minority stigma "get under the skin"? A psychological mediation framework. Psychological Bulletin, 135(5), 707-730. https://doi.org/10.1037/a0016441

Herek, G. M. (2004). Beyond "Homophobia ": Thinking About Sexual Prejudice and Stigma 
in the Twenty-First Century. Sexuality Research \& Social Policy, 1(2), 6-24.

Hickson, F., Reid, D., Weatherburn, P., Stephens, M., Nutland, W., \& Boakye, P. (2004). HIV, sexual risk, and ethnicity among men in England who have sex with men. Sexually Transmitted Infections, 80(6), 443-450. https://doi.org/10.1136/sti.2004.010520

Jaspal, R. (2012). Coping with Religious and Cultural Homophobia : Emotion and Narratives of Identity Threat among British Muslim Gay Men. In Nynäs P and Yip AKT (eds) Religion, Gender and Sexuality in Everyday Life (pp. 71-90). Farnham, Surrey: Ashgate Publishing

Jaspal, R. (2014). Arranged Marriage, Identity, and Well-being among British Asian Gay Men. Journal of GLBT Family Studies, 10(5), 425-448. https://doi.org/10.1080/1550428X.2013.846105

Jaspal, R. (2018). Enhancing Sexual Health, Self-Identity and Wellbeing Among Men Who Have Sex With Men: A Guide for Practitioners.London: Jessica Kingsley Publishers.

Jaspal, R. (2020). Honour beliefs and identity among British South Asian gay men. In M.M. Idriss (eds), Men, Masculinities and Honour-Based Abuse. London: Routledge.

Jaspal, R., \& Cinnirella, M. (2010). Coping with potentially incompatible identities: Accounts of religious, ethnic, and sexual identities from british pakistani men who identify as muslim and gay. British Journal of Social Psychology, 49(4), 849-870. doi:10.1348/014466609X485025

Jaspal, R., \& Cinnirella, M. (2014). Hyper-affiliation to the religious in-group among british pakistani muslim gay men: Hyper-affiliation to the religion in-group. Journal of Community \& Applied Social Psychology, 24(4), 265-277. doi:10.1002/casp.2163

Jaspal, R. and Coyle, A. (2009) Reconciling social psychology and socio-linguistics can have some benefits: language and identity among second generation British Asians. Social Psychological Review, 11 (2), pp. 3-14.

Jaspal, R., Lopes, B., Jamal, Z., Paccoud, I., \& Sekhon, P. (2017). Sexual abuse and HIV-risk behaviour among black and minority ethnic men who have sex with men in the UK. Mental Health, Religion and Culture, 20(8), 841-853. https://doi.org/10.1080/13674676.2017.1414170

Jaspal, R., \& Siraj, A. (2011). Perceptions of 'coming out' among British Muslim gay men. Psychology \& Sexuality, 2(3), 183-197. https://doi.org/10.1080/19419899.2010.526627

Keogh, P., Henderson, L., \& Dodds, C. (2004). Ethnic Minority Gay Men: Redefining community, restoring identity. University of Portsmouth, Portsmouth: Sigma Research.

Kim, H. J., \& Fredriksen-Goldsen, K. I. (2013). Nonresponse to a question on self-identified sexual orientation in a public health survey and its relationship to race and ethnicity. American Journal of Public Health, 103(1), 67-69. https://doi.org/10.2105/AJPH.2012.300835

Kim, S., Thibodeau, R., \& Jorgensen, R. S. (2011). Shame, Guilt, and Depressive Symptoms: A Meta-Analytic Review. Psychological Bulletin, 137(1), 68-96. https://doi.org/10.1037/a0021466

King, M., McKeown, E., Warner, J., Ramsay, A., Johnson, K., Cort, C., . . . Davidson, O. (2003). Mental health and quality of life of gay men and lesbians in england and wales: 
Controlled, cross-sectional study. The British Journal of Psychiatry, 183(6), 552-558. doi:10.1192/bjp.183.6.552

King, M., Semlyen, J., Tai, S. S., Killaspy, H., Osborn, D., Popelyuk, D., \& Nazareth, I. (2008). A systematic review of mental disorder, suicide, and deliberate self harm in lesbian, gay and bisexual people. BMC Psychiatry, 8(1), 70-70. doi:10.1186/1471-244X$8-70$

Klonsky, E. D. (2007). The functions of deliberate self-injury: A review of the evidence. Clinical Psychology Review, 27(2), 226-239. https://doi.org/10.1016/j.cpr.2006.08.002

Lazarus, R. S. (1999). Stress and emotion: A new synthesis. New York, NY, US: Springer Publishing Co.

Lazarus, R. S., \& Folkman, S. (1984). Stress, appraisal, and coping. New York: Springer.

Marmot, M. (2010), Fair society, Healthy lives: The Marmot Review: Strategic Review of Health Inequalities in England post-2010. Retrived from:

https://www.parliament.uk/documents/fair-society-healthy-lives-full-report.pdf

McDermott, E., Hughes, E., \& Rawlings, V. (2018). The social determinants of lesbian, gay, bisexual and transgender youth suicidality in England: a mixed methods study. Journal of Public Health, 40(3), e244-e251. https://doi.org/10.1093/pubmed/fdx135

McKeown, E., Doerner, R., Nelson, S., Low, N., Robinson, A., Anderson, J., \& Elford, J. (2012). The experiences of ethnic minority MSM using NHS sexual health clinics in britain. Sexually Transmitted Infections, 88(8), 595-600. doi:10.1136/sextrans-2011050436

McNair, R. P., Hegarty, K., \& Taft, A. (2012). From silence to sensitivity: A new Identity Disclosure model to facilitate disclosure for same-sex attracted women in general practice consultations. Social Science and Medicine, 75(1), 208-216. https://doi.org/10.1016/j.socscimed.2012.02.037

Mereish, E. H., \& Bradford, J. B. (2014). Intersecting Identities and Substance Use Problems : Sexual Orientation, Gender, Race, and Lifetime Substance. Journal Studies on Alcohol and Drugs, 75(1), 179-188.

Meyer, I. H. (2003). Prejudice, social stress, and mental health in lesbian, gay, and bisexual populations: conceptual issues and research evidence. Psychological Bulletin, 129(5), 674-697. https://doi.org/10.1037/0033-2909.129.5.674

Meyer, I. H., \& Dean, L. (1998). Internalized homophobia, intimacy, and sexual behavior among gay and bisexual men. In Stigma and sexual orientation: Understanding prejudice against lesbians, gay men, and bisexuals. (pp. 160-186). Thousand Oaks, CA, US: Sage Publications, Inc. https://doi.org/10.4135/9781452243818.n8

Meyer, I. H., Dietrich, J., \& Schwartz, S. (2008). Lifetime prevalence of mental disorders and suicide attempts in diverse lesbian, gay, and bisexual populations. American Journal of Public Health, 98(6), 1004-1006. https://doi.org/10.2105/AJPH.2006.096826

Morris, J. F., Waldo, C. R., \& Rothblum, E. D. (2001). A model of predictors and outcomes of outness among lesbian and bisexual women. American Journal of Orthopsychiatry, 71(1), 61-71. https://doi.org/10.1037/0002-9432.71.1.61

Mustanski, B. S., Garofalo, R., \& Emerson, E. M. (2010). Mental health disorders, 
psychological distress, and suicidality in a diverse sample of lesbian, gay, bisexual, and transgender youths. American Journal of Public Health, 100(12), 2426-2432. https://doi.org/10.2105/AJPH.2009.178319

Nazroo, J. Y. (2003). The structuring of ethnic inequalities in health: economic position, racial discrimination, and racism. American Journal of Public Health, 93(2), 277-84.

Newcomb, M. E., \& Mustanski, B. (2010). Internalized homophobia and internalizing mental health problems: A meta-analytic review. Clinical Psychology Review, 30(8), 10191029. https://doi.org/10.1016/j.cpr.2010.07.003

Office for National Statistics (2011). Ethnicity and National Identity in England and Wales: 2011. Retrieved from: https://www.ons.gov.uk/peoplepopulationandcommunity/culturalidentity/ethnicity/articl es/ethnicityandnationalidentityinenglandandwales/2012-12-11

Oyserman, D., Coon, H. M., \& Kemmelmeier, M. (2002). Rethinking individualism and collectivism: Evaluation of theoretical assumptions and meta-analyses. Psychological Bulletin, 128(1), 3-52. https://doi.org/10.1037//0033-2909.128.1.3

Pachankis, J. E. (2007). The psychological implications of concealing a stigma: A cognitiveaffective-behavioral model. Psychological Bulletin, 133(2), 328-345. https://doi.org/10.1037/0033-2909.133.2.328

Palinkas, L. A., Horwitz, S. M., Green, C. A., Wisdom, J. P., Duan, N., \& Hoagwood, K. (2015). Purposeful Sampling for Qualitative Data Collection and Analysis in Mixed Method Implementation Research. Adm. Policy Ment. Health, 42(5), 2-4. https://doi.org/10.1007/s10488-013-0528-y.Purposeful

Plöderl, M., Wagenmakers, E., Tremblay, P., Ramsay, R., Kralovec, K., Fartacek, C., \& Fartacek, R. (2013). Suicide risk and sexual orientation: A critical review. Archives of Sexual Behavior, 42(5), 715-727. doi:10.1007/s10508-012-0056-y

Quinn, D. M., \& Chaudoir, S. R. (2009). Living With a Concealable Stigmatized Identity: The Impact of Anticipated Stigma , Centrality , Salience , and Cultural Stigma on Psychological Distress and Health, 97(4), 634-651. https://doi.org/10.1037/a0015815

Quinn, D. M., Williams, M. K., Quintana, F., Gaskins, J. L., Overstreet, N. M., Pishori, A., ... Chaudoir, S. R. (2014). Examining effects of anticipated stigma, centrality, salience, internalization, and outness on psychological distress for people with concealable stigmatized identities. PLOS ONE, 9(5). https://doi.org/10.1371/journal.pone.0096977

Ream, G. L. \& Savin-Williams, R. C. (2005). Reconciling Christianity and positive nonheterosexual identity in adolescence, with implication for psychological wellbeing. Journal of Gay \& Lesbian Issues in Education, 3(2), 19-36.

Rich, A. (1980). "Compulsory Heterosexuality and Lesbian Existence.” Signs: Journal of Women in Culture and Society 5 (4) 631-660.

Ragins, B., Singh, R., \& Cornwell, J. M. (2007). Making the Invisible Visible: Fear and Disclosure of Sexual Orientation at Work. Journal of Applied Psychology, 92(4), 11031118. https://doi.org/10.1037/0021-9010.92.4.1103

Ryan, C. \& Futterman, D. (1998). Lesbian \& gay youth: Care and counseling. New York: Columbia University 
Schrimshaw, E. W., Siegel, K., Downing, J. M. J., \& Parsons, J. T. (2013). Disclosure and concealment of sexual orientation and the mental health of non-gay-identified, behaviorally-bisexual men. Journal of Consulting and Clinical Psychology, 81(1), 141153. https://doi.org/10.1037/a0031272.

Semlyen, J., King, M., Varney, J., \& Hagger-Johnson, G. (2016). Sexual orientation and symptoms of common mental disorder or low wellbeing: Combined meta-analysis of 12 UK population health surveys. Bmc Psychiatry, 16, 67. doi:10.1186/s12888-016-0767-z

Silenzio, V. M. B., Pena, J. B., Duberstein, P. R., Cerel, J., \& Knox, K. L. (2007). Sexual orientation and risk factors for suicidal ideation and suicide attempts among adolescents and young adults. American Journal of Public Health, 97(11), 2017-2019. https://doi.org/10.2105/AJPH.2006.095943

Siraj, A. (2009). The Construction of the Homosexual "Other" by Muslim Heterosexuals. Contemporary Islam, 3(1): 41-57 3.

Siraj, A. (2011). Isolated, invisible, and in the closet: the life story of a Scottish Muslim lesbian. Journal of Lesbian Studies, 15(1), 99-121. https://doi.org/10.1080/10894160.2010.490503

Siraj, A. (2018a) British Pakistani lesbians existing within the confines of the closet. Culture, Health \& Sexuality 20 (1), pages 28-39.

Siraj, A. (2018b) Sexuality in the shadows of a friendship: An intimate portrayal of friendship between two British Pakistani lesbians. Journal of Lesbian Studies, 22(1), 43-53.

Soni, S., Bond, K., Fox, E., Grieve, A. P., \& Sethi, G. (2008). Black and minority ethnic men who have sex with men: a London genitourinary medicine clinic experience. International Journal of STD

Sung, M. R., Szymanski, D. M., \& Henrichs-beck, C. (2015). Challenges , Coping , and Benefits of Being an Asian American Lesbian or Bisexual Woman. American Psychological Association, 2(1), 52-64.

Szymanski, D. M., Kashubeck-West, S., \& Meyer, J. (2008). Internalized Heterosexism: Measurement, Psychosocial Correlates, and Research Directions. The Counseling Psychologist, 36(4), 525-574. https://doi.org/10.1177/0011000007309489

Szymanski, D., \& Sung, M. (2010). Minority stress and psychological distress among asian american sexual minority persons. Counseling Psychologist, 38(6), 848-872. doi:10.1177/0011000010366167

Stonewall (2012), “One minority at a time: Being black and gay”. Retrieved from: http://www.stonewall.org.uk/documents/one_minority_at_a_time_final.pdf

Tilghman-Osborne, C., Cole, D. A., \& Felton, J. W. (2010). Definition and measurement of guilt: Implications for clinical research and practice. Clinical psychology review, 30(5), 536-46.

Toor, S. (2009). British Asian girls, crime and youth justice. Youth Justice, 9(3), 239-253. https://doi.org/10.1177/1473225409345102

Wagner, E. F., Myers, M. G., \& McIninch, J. L. (1999). Stress-coping and temptation-coping as predictors of adolescent substance use. Addictive Behaviors, 24(6), 769-779. 
https://doi.org/10.1016/S0306-4603(99)00058-1

Warner, J., McKeown, É., Griffin, M., Johnson, K., Ramsay, A., Cort, C., \& King, M. (2004). Rates and predictors of mental illness in gay men, lesbians and bisexual men and women: Results from a survey based in England and Wales. British Journal of Psychiatry, 185, 479-485. https://doi.org/10.1192/bjp.185.6.479

Williamson, I. R. (2000). Internalized homophobia and health issues affecting lesbians and gay men. Health Education Research, 15(1), 97-107.

Yip, A. K. T. (2004a). Negotiating space with family and kin in identity construction: the narratives of British non-heterosexual Muslims. The Sociological Review, 52(3), 336350. https://doi.org/10.1111/j.1467-954X.2004.00483.x

Yip, A. K. T. (2004b) 'Embracing Allah and Sexuality?: South Asian Non-heterosexual Muslims in Britain', in P. Kumar and K. Jacobsen (editors) South Asians in the Diaspora. Leiden: EJ Brill. 